\title{
Ezagutzan Oinarritutako Giza Jardueren Eredu Dinamiko eta Pertsonalizatuak Ikasten
}

\author{
Gorka Azkune*, Aitor Almeida, Diego López-de-Ipiña \\ DeustoTech-Deustuko Unibertsitatea, \\ Avenida de las Universidades 24, 48007 Bilbo \\ Liming Chen
}

School of Computer Science and Informatics-De Montfort University, LE19BH Leicester (Erresuma Batua)

*gorka.azkune@deusto.es

DOI: 10.1387/ekaia.14662

Laburpena: Gizakietara egokitutako teknologiak garatzeko, ezinbestekoa da makinek giza jarduerak antzemateko gaitasuna izatea, sentsoreak eta konputazio-gailuak erabiliz. Horretarako, antzeman nahi diren jarduera horien eredu konputazionalak sortu behar dira. Gaur egun, jarduera-ereduak sortzeko garaian, bi joera nagusi aurki daitezke: datuetan oinarritutako ereduak eta ezagutzan oinarritutakoak. Biek ere abantaila eta desabantailak dituzte. Lan honen helburua da bi joerak elkartzea eredu dinamiko eta pertsonalizatuak lortzeko, ezagutzan oinarritutako eredu orokor batzuetatik hasita. Modu horretan, pertsona bakoitzaren bilakaerara egokitutako modelatze-prozesuak lor daitezke.

Hitz gakoak: Giza jarduera ereduak, ezagutzan oinarritutako ereduak, ikasketa automatikoa.

Abstract: Being able to recognise human activities by means of sensor and computational devices can be a key competence in order to achieve human centred technologies. For that purpose, it is mandatory to build computational models of the activities which have to be recognised. There are two major approaches for activity modelling: the data-driven and the knowledge-driven approaches. Both of them have advantages and drawbacks. The objective of this work is to combine both modelling approaches with the aim of building dynamic and personalised activity models, using generic knowledge-based models. This would allow implementing modelling processes which can adapt themselves to the evolution of specific people.

Keywords: Human activity modelling, knowledge-based models, machine learning. 


\section{SARRERA}

Giza jarduerak antzemateko gaitasunak eragin handia izan dezake hainbat aplikazio esparrutan, hala nola, ingurune adimentsuak [1], robotika soziala [2] edo bideo bidezko zaintza [3]. Ingurune adimentsuetan, giza jarduerak antzemateko gaitasunak ate asko ireki eta hainbat aukera berri ekar ditzake, hala nola pertsona baten portaeran aldaketak antzeman eta gaixotasunekin korrelazionatu, zailtasunak dituzten pertsonei laguntza eman jarduera zehatz batzuetan, bizimodu osasuntsu bat egiteko aholkuak eman eta beste hainbat aplikazio interesgarri. Robotika sozialean, berriz, gizakien eta roboten arteko harremanak askoz naturalagoak bilaka daitezke, robotak giza jarduerak interpretatzeko gaitasuna baldin badu. Alde praktikoari begiratuta, robot batek gizaki batekin kolaboratu ahalko luke ataza bat egiteko. Azkenik, bideo bidezko zaintzan, ezohiko portaerak antzeman daitezke eta hainbat egoera arriskutsu ekidin.

Oro har, giza jarduerak antzemateak berebiziko garrantzia izan dezake erabiltzaileetara egokitzen diren teknologietan. Balizko teknologia adimentsu horiek gai izan beharko lukete erabiltzailearen unean uneko jardueretara egokitzeko, zerbitzu pertsonalizatua eskaintzeko.

Giza jarduerak antzemateko sistema batek hiru zati nagusi izan ohi ditu: monitorizazio-sistema, jarduera ereduak eta jarduerak antzemateko algoritmoak. Monitorizazio-sistemak sentsorez osatuta egoten dira eta eskuarki bi talde handi bereizten dira: ikusmen artifizialean oinarritutako monitorizazio-sistemak eta sentsore-sareetan oinarritutakoak [4]. Lan hau bigarren taldean koka daiteke. Zehatz azalduta, giza jardueren informazioa bilduko da jarduera horiek exekutatzeko erabili behar diren objektuak monitorizatzen dituzten sentsore sinple batzuen bidez. Sentsore horiek objektuarekin elkarrekintza dagoenentz adieraziko dute.

Sistemaren bigarren zatia jarduera-ereduena da. Jarduera-ereduek gizakiok jarduera zehatz batzuk nola exekutatzen ditugun deskribatzeko balio dute. Deskribapen horiek modu konputazionalean egiten dira; hots, ordenagailuek ulertu eta erabiltzeko moduan. Hasteko, interesgarria da ekintza eta jarduera kontzeptuen arteko ezberdintasuna azaltzea. Ekintza bat instant batean gauzatzen den gertaera bat da. Adibidez, edalontzi bat hartzea ekintza bat da. Jarduera bat, berriz, denboran zehar hedatzen den ekintzasekuentzia bat izaten da. Kafea prestatzea, esaterako, jarduera bat da, non hainbat ekintza burutu behar diren: edalontzi bat hartu, kafea hartu, kafeontzia hartu, urez bete eta abar. Eredu konputazional horiek ezinbestekoak dira jarduerak antzemateko, eta haiek modelatzeko bi joera nagusi bereiz daitezke. Alde batetik, datuetan oinarritutako ereduak daude. Monitorizazio sistematik jasotako datuak erabiltzen dira zuzenean jarduera-ereduak sortzeko, ikasketa automatikoa erabiliz. Horrela, jarduera-eredu pertsonalizatuak lortzen dira, pertsona zehatz baten datuetan oinarritzen baitira. Bes- 
tetik, ezagutzan oinarritutako ereduak daude. Haien kasuan, domeinuari eta jarduerei buruz aldez aurretik dagoen ezagutza erabiltzen da eredu orokorrak sortzeko. Eredu orokorrak edozein erabiltzaileri aplika dakizkioke, ereduek jardueren ezaugarri orokorrak biltzen baitituzte eta ez pertsona batek jarduera hori exekutatzeko duen modu berezia.

Datuetan oinarritutako prozesuek eta ezagutzan oinarritutakoek ezaugarri kontrajarriak dituzte askotan (ikus 1 taula). Hori dela eta, interesgarria litzateke bi teknikok elkartzea jarduera-ereduak sortzeko prozesu bakarrean, modu horretara bakoitzaren ezaugarri onenei etekina ateratzeko.

1. taula. Datuetan eta ezagutzan oinarritutako jarduera-ereduak sortzeko prozesuen ezaugarri kontrajarriak.

\begin{tabular}{lcc}
\hline \multicolumn{1}{c}{ Ezaugarria } & $\begin{array}{c}\text { Datuetan } \\
\text { oinarritutakoak }\end{array}$ & $\begin{array}{c}\text { Ezagutzan } \\
\text { oinarritutakoak }\end{array}$ \\
\hline Eredu orokorrak & $\mathrm{Ez}$ & $\mathrm{Bai}$ \\
Eredu perstonalizatuak & $\mathrm{Bai}$ & $\mathrm{Ez}$ \\
Eredu dinamikoak & $\mathrm{Bai}$ & $\mathrm{Ez}$ \\
Denbora eta ziurgabetasuna kudeatu & $\mathrm{Ongi}$ & $\mathrm{Gaizki}$ \\
Datuen beharra & $\mathrm{Bai}$ & $\mathrm{Ez}$ \\
Domeinuaren ezagutzaren beharra & $\mathrm{Ez}$ & $\mathrm{Bai}$ \\
Eredu ulergarriak & $\mathrm{Ez}$ & $\mathrm{Bai}$ \\
\hline
\end{tabular}

Lan honen helburua hain zuzen ere bide horretan pauso esanguratsuak ematea da. Zehatz esanda, ezagutzan oinarritutako eredu orokorrak hartuko dira oinarritzat, hots, edozein erabiltzaileren jarduerak deskribatzeko gai diren ereduak. Ondoren, pertsona zehatz baten datuak bilduz, datuetan oinarritutako ikasketa-algoritmoak garatuko dira, hasierako eredu orokorrak osatzeko informazio pertsonalarekin. Emaitza gisa, jarduera-ereduen prozesu berri bat lortuko da, non eredu orokorrak, pertsonalizatuak, dinamikoak eta ulergarriak konbinatuko diren. Ez dira kontuan hartuko lan honetan denboraren kudeaketa eta ziurgabetasunaren kudeaketa jardueraereduetan.

\section{ARLOKO EGOERA}

Jarduera-eredu bat sortzeko garaian hainbat parametro hartu behar dira kontuan. Lan batetik bestera ereduek biltzen duten informazioa alda daitekeen arren, oro har beti agertzen diren parametro batzuk daude: ekintza-sekuentzia, ekintzen arteko denbora-tarteak, iraupena, erabilitako objektuak 
eta jarduera noiz eta non exekutatu den. Parametro horiekin, zehaztasun handiz deskriba daiteke jarduera bat. Baina era batera edo bestera, parametro horiek guztiak lortu behar dira antzeman nahi diren jarduera guztietarako. Eta hor sartzen da jokuan modelatze prozesua; hots, jarduera-ereduak sortzeko prozesua. Jarduerak modelatzeko prozesuak bi joera handitan banatzen dira, 1 atalean jada aipatu den bezala. Alde batetik, datuetan oinarritutako ereduak ditugu eta, bestetik, ezagutzan oinarritutakoak.

Bi joeren ezaugarri kontrajarriak direla eta, modelatze prozesu hibridoak ere agertu dira azken aldian. Datuetan oinarritutako modelatze prozesuek pertsona batek jarduerak exekutatzean bildutako sentsoreen datuak hartzen dituzte oinarri. Ideia nagusia jarduera-ereduen parametroak datu horietatik ateratzea da, ikasketa automatikoa erabiliz horretarako. Ikasketa automatikoa adimen artifizialaren esparruan koka daiteke. Haren helburua, ordenagailuek arazo bat nola konpondu bere kasa ikastea da, horretarako arazo zehatz horren inguruko datuak kontuan hartuz.

Ikertzaile batzuek ikasketa gainbegiratua darabilte. Teknika horren ideia nagusia da datu-base batean pertsona bat monitorizatzean lortu diren sentsore-datuak bildu eta datu horiek deskribatzen dituzten jarduerak zeintzuk diren adieraztea. Mota horretako datu-baseei etiketatuak deritze. Datubase etiketatu horien gainean ikasketa-algoritmo ezberdinak erabil daitezke jarduera-ereduak ikasteko. Adibidez: Naive-Bayes sailkatzaileak [5], Markov-en kate ezkutuak [6] edo sare bayesiar dinamikoak [7].

Ikasketa ez-gainbegiratuan oinarritutako modelatze-prozesuak ere agertu dira. Kasu horietan, datu-baseak ez daude etiketatuak; hots, badago sentsoreen informazioa, baina ez dakigu zer jarduera ari diren deskribatzen. Adibide bereziki ona Rashidi eta Cook autoreek 2013ko lanean [8] aurkezten duten modelatze prozesua da. Oro har, datuetan oinarritutako modelatze-prozesuek oso ondo maneiatzen dituzte denbora (jardueren iraupena, ekintzen arteko tartea edo jarduera noiz exekutatzen den) eta ziurgabetsuna (sentsoreen erroreen ondorioz informazioa ez da ziurra), eredu estatistiko eta probabilistikoak erabiltzen baitituzte. Gainera, pertsona baten datuetan oinarritzen direnez, sortzen diren ereduak pertsonalizatuak eta dinamikoak dira, eta gai dira edozein aldaketa jardueren exekuzioan modelatzeko. Baina desabantailak ere nabarmenak dira: (i) datu-base etiketatuen beharra oso dependentzia gogorra da, (ii) ikasitako ereduak ezin dira orokortu (pertsona eta ingurune berri bakoitzeko, berriro egin behar da ikasketa) eta (iii) ereduak berak ez dira ulergarriak gizakientzat, beren izaera estatistiko eta probabilistokoa dela medio.

Ezagutzan oinarritutako modelatze-prozesuek beste ikuspegi batetik egiten dute lan. Datuak erabili beharrean, aldez aurretik dagoen ezagutza probesten dute ereduak sortzeko. Jakina da, kafe bat prestatzeko, kafea, edalontzi bat eta beste objektu batzuk behar direla. Oro har, kafe bat presta- 


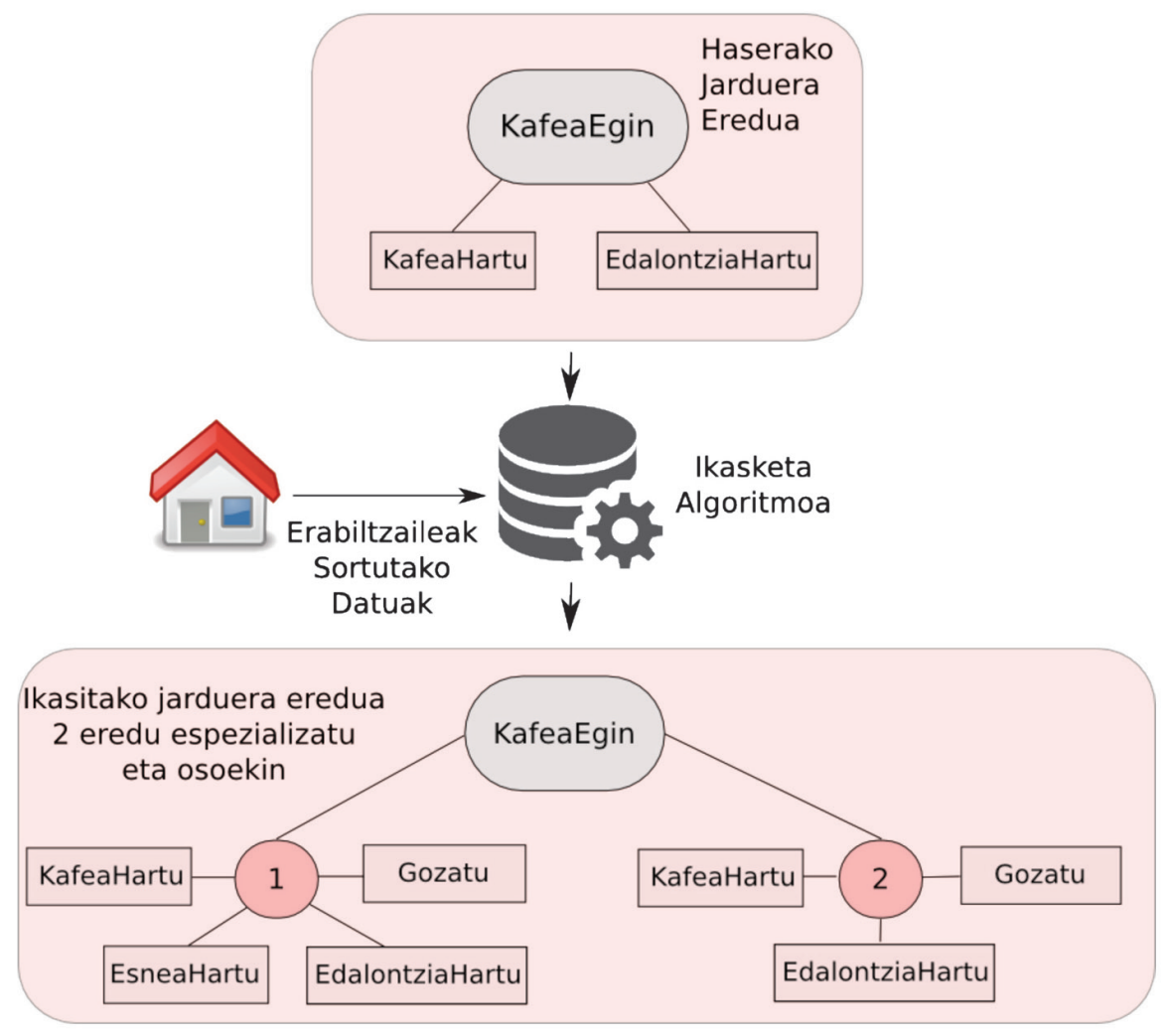

1. irudia. Lan honetan lortu nahi den helburua: hasierako jarduera-eredu orokor bat edukita eta pertsona zehatz baten datuak jasota, ikasi jarduera horren eredu oso eta espezializatuak.

tzeko bost minutu inguru behar izaten dira. Modu horretako ezagutzaz baliatuz, ikertzaile batzuek eredu logikoak sortzen dituzte $[9,10]$. Beste ikertzaile batzuek, berriz, Web Semantikaren oinarri den OWL (Web Ontology Language) lengoaia darabilte jarduerak deskribatzeko [11, 12]. OWL lengoaia ezagutza errepresantatzeko erabiltzen den formalismo bat da. Haren abantaila nagusietako bat da errepresentatzen den ezagutzaren gainean arrazoiketa teknika ezberdinak aplika daitezkeela. Modelatze-prozesu horien abantailak honakoak dira: (i) eredu orokorrak sortzen dira, edozein erabiltzaileri aplikatzeko modukoak, (ii) ez dago datuekiko menpekotasunik eta (iii) ereduek egitura logiko eta semantikoak jarraitzen dituztenez, gizakiok erraz uler ditzakegu eta, beraz, beste ataza askotarako erabil ditzakegu. Desabantailak ere badaude, ordea: (i) ezin dira eredu pertsonalizatuak sortu pertsona bakoitzarentzat, ezin baita aldez aurretik jakin pertsona batek zer 
egingo duen, (ii) ereduak estatikoak dira, hots, behin definituz gero, ez dira egokitzen pertsona baten aldaketetara eta (iii) denbora eta ziurgabetasuna behar bezala kudeatzeko zailtasun handiak dituzte.

Bi modelatze-prozesuon ezaugarri kontrajarriak direla eta (ikus 1 taula), jada agertu dira prozesu hibrido batzuk ere. Aipagarriena, ziurrenik, Chen et al. autoreek dakartena da [13]. Bertan, ezagutzan oinarritutako ereduak hartzen dituzte oinarritzat. Baina pertsona baten datuetan oinarrituta, hasierako jarduera horien profil pertsonalizatuak ikasten dituzte. Profil horietan jarduera noiz exekutatzen den, erabiltzen diren objektu zehatzak eta jardueraren iraupena bezalako parametroak agertzen dira. Horiek guztiak ikasketa bidez lortzen dituzte eredu orokorrak eta datuak nahastuz. Chen et al. autoreen ikuspegian pertsona guztiek ekintza sekuentzia berdinak exekutatzen dituzte jarduera bera exekutatzeko. Horrela, haien arabera mundu guztiak ekintza berdinak exekutatuko lituzke kafe bat prestazeko orduan. Baina hori ez da horrela. Pertsona bakoitzak ekintza ezberdinak exekuta ditzake jarduera bera exekutatzeko orduan. Adibidez, batzuek esnea jartzen diote kafeari, baina beste batzuek ez. Ekintza zehatz horiek ezinbesteko papera betetzen dute eredu pertsonalizatuak sortzeko, eta ezin dira aldez aurretik jakin.

\section{MODELATZE PROZESU BERRIAK}

\subsection{Oinarriak}

Jarduera bat osatzen duten ekintzak zehaztea oso garrantzitsua da jarduera hori behar bezala antzemateko. Oro har, jakintzat ematen da algoritmo gehienek ekintza horiek aurrez ezagutzen dituztela, baina abiapuntu hori ez da zuzena pertsona ezberdinekin lan egitean. Aditu batek ezin du aldez aurretik jakin edozein pertsonak exekuta ditzakeen ekintzak zeintzuk diren jarduera bakoitzarentzat; beraz, ekintza horiek ikasi egin behar dira.

Lan honetan, aditu batek aldez aurretik sor ditzakeen jarduera-ereduek mundu guztiak exekutatzen dituen ekintzak biltzen dituela da gure abiapuntua. Hau da, jarduera bat exekutatzeko behar diren derrigorrezko ekintzak bakarrik gordeko dira hasierako jarduera-ereduetan. Adibidez, kafe bat prestatzeko, ezinbestekoa da kafea bera eta edalontzi bat hartzea. Ez dago inor munduan ekintza horiek exekutatu gabe kafe bat prestatzeko gai denik. Beraz, hasierako jarduera-ereduak bi ekintza horiek izango ditu: kafea hartu eta edalontzia hartu. Pertsona bakoitzak exekuta ditzakeen bestelako ekintzak modelatze-prozesu automatikoak ikasiko ditu, eredu oso eta espezializatuak lortzeko (ikusi 1 irudia).

Beraz, gure modelatze-sistema berriak sarrera gisa hartuko ditu haserako jarduera eredu orokorrak. Ereduok ezagutzan oinarritutakoak izango dira, aditu batek emango baititu. Bestalde, sentsore sare bat erabiliz, per- 
tsona batek erabiltzen dituen objektuen trazak bilduko dira. Informazio boolearra izango da jasotakoa, hau da, objektuarekin elkarrekintza dagoen ala ez soilik dioena. Jasotako datuak erabilita eta haserako jarduera ereduak erabiliz, eredu oso eta espezializatuak lortuko dira ikasketa-prozesuan.

\subsection{Garatutako modelatze prozesua}

Ekintza pertsonalizatuak ikasteko arazoari aurre egiteko, bi pausotako prozesua diseinatu da. Lehenik eta behin, hasierako jarduera-ereduak erabiliz, clustering algoritmo berezi bat inplementatu da. Bertan, hasieraketa fase bat dago (Semantic Activity Annotation ala SA ${ }^{3}$ algoritmoa), non hasierako ereduak bilatzen diren sentsore datu-basean, patroien errekonozimendu algoritmo bat erabiliz (pattern recognition). Modu horretan, datu-basean jarduera ezberdinak gertatzen diren hasierako denbora tarteen lehen estimazioa lortuko da. Horren ondoren, bigarren fasean (Action Aggregator ala AA algoritmoa), hasierako cluster horietatik kanpora geratu diren ekintzak aztertzen dira. Azterketa horretan ekintza bakoitzaren mota, lekua eta denbora hartzen dira kontuan, erabakitzeko ea ekintza bakoitza zein jardueratan doan. Clustering algoritmo horren emaitza jarduera bakoitzeko ekintza-sekuentzia ezberdinak dira, edo bestela esanda, ekintza-clusterrak. Azken cluster horiek erabiltzen dira modelatze-algoritmoan (Activity Model Learner ala AML). Bertan, elementu arraroak bilatzeko algoritmo estatistiko bat inplementatu da, ekintza-cluster faltsuak zeintzuk diren jakiteko. Cluster faltsu horiek sentsoreen erroreak, pertsona bakoitzaren hutsegiteak edo eta clustering algoritmoaren erroreen ondorioz ager daitezke. Faltsuak ez diren ekintza-clusterrak izango dira, azkenik, jarduera-eredu oso eta espezializatuak. Deskribatu berri dugun prozesua 22 . irudian ikus daiteke.

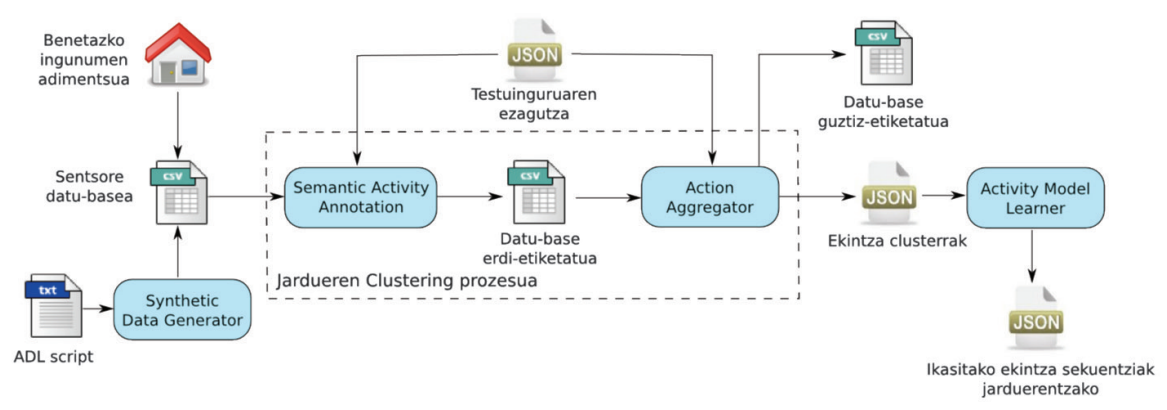

2. irudia. Garatutako modelatze-prozesuaren software arkitektura.

Modelatze-prozesua osatzen duten algoritmoak berritzaileak dira hainbat esparrutan. Clustering prozesuak, lehendabizikoz, hasierako jarduera- 
ereduak darabiltza ekintza-clusterrak topatu eta etiketatzeko. Oro har, clustering algoritmoek datu-base batean dagoen egitura bilatzen dute, baina klase bakoitzari ezin izaten diote etiketarik esleitu. Kasu honetan, ordea, hasierako ereduak erabiliz bi gauzak batera egitea lortzen da: egitura topatzea (ekintza-clusterrak) eta etiketatzea (jarduera-izenak esleitu cluster bakoitzari). Bestalde, AML algoritmoak ekintza clusterren antzekotasuna kalkulatzen du, jada definituriko metrika batzuk erabiliz. Elementu arraroak topatzeko orduan, antzekotasun-espazioan egiten du lan. Oso antzekoak diren ekintza-clusterrak elkarrekin fusionatzen ditu, eta jarduera-ereduak lortzen ditu horrela.

\subsection{Ebaluazio-metodologia eta emaitzak}

Lan honetan garatutako modelatze-prozesua behar bezala ebaluatzeko, metodologia berri bat jarri da martxan. Zailtasun handiko zeregina da ingurune sentsorizatu batean pertsona kopuru on batekin hainbat egunez esperimentuak egitea, eta beraz, datu-base publikoak erabili ohi dira (beste iker-talde batek egindako esperimentuek sortutako datuak). Baina tamalez, datu-base publiko horietan ezin izan dugu datu-base egokirik topatu modelatze-prozesua ebaluatzeko. Beraz, simulazio-teknikak erabili dira lan honetan.

Simulazio-tekniken arazo handiena pertsonen jokabidea modelatzea izaten da. Lan honetan, arazo hori gainditzeko, inkestak egin zaizkie hainbat pertsonari, langai diren jarduerak nola exekutatzen dituzten jakiteko. Informazio hori simulatzaile berezi bati eman zaio eta hark egun ugaritarako datuak sortzen ditu pertsona bakoitzeko. Simulatzaileak sentsoreen erroreak eta pertsonen portaera-aldaketak simula ditzake, datu errealistak sortzeko.

Modelatze-prozesua ebaluatzeko, zortzi pertsonaren informazioa erabili da. Zazpi jarduera ezberdin definitu dira, eta zortzi pertsona horien deskribapenak erabiliz, 60 egunetako datu-baseak sortu dira pertsonako. Modelatze-prozesuaren konfigurazio onenean emaitza oso positiboak lortu dira. Jarduera bakoitzaren bilakaera edo aldaera ezberdin guztiak ikasi ahal izan dira, 2 taulan ikus daitekeen bezala. Pertsona bakoitzak jarduera bakoitza modu ezberdinetan exekuta dezake (ekintza-sekuentzia ezberdinak). Taulan, zortzi pertsonarentzako batez besteko datuak agertzen dira. Adibidez, pasta prestatzeko jarduera batez beste bi era ezberdinetan exekutatzen dute zortzi pertsonak (batezbesteko aldaerak). Modelatze-prozesuak bi era horiek ongi ikasten ditu, baina batez beste 1,12 eredu faltsu ere ikasten ditu. Kontuan izanda simulatzailean jarri den sentsore-errore tasa oso handia dela, emaitzak oso ontzat jo daitezke.

Argi gera dadin ekintza pertsonalizatuak ikastearen garrantzia, 3 taulan informazio interesgarria erakusten da. Bertan, jarduera bakoitzeko adi- 
2. taula. Modelatze-prozesuaren emaitzak, zortzi pertsonarentzako batezbesteko gisa.

\begin{tabular}{l|ccc|c}
\hline \multirow{2}{*}{\multicolumn{1}{c|}{ Jarduera }} & \multicolumn{3}{|c|}{ Ikasketaren emaitzak } & \multirow{2}{*}{$\begin{array}{c}\text { Batez besteko } \\
\text { aldaerak }\end{array}$} \\
\cline { 2 - 3 } & Eredu zuzenak & Eredu faltsuak & Ereduak guztira & \\
\hline Txokolatea prestatu & 1 & 1,2 & 2,2 & 1 \\
Telebista ikusi & 1,14 & 0,89 & 2,03 & 1,14 \\
Hortzak garbitu & 1,25 & 1,17 & 2,42 & 1,25 \\
Eskuak garbitu & 1 & 0,75 & 1,75 & 1 \\
Pasta prestatu & 2 & 1,12 & 3,12 & 2 \\
Liburua irakurri & 1,12 & 0,14 & 1,26 & 1,12 \\
Kafea prestatu & 1,71 & 1,71 & 3,42 & 1,71 \\
\hline
\end{tabular}

tuak identifikatu ahal izan duen derrigorrezko ekintza kopurua agertzen da (ekintzak hasieran). Hurrengo zutabean modelatze-prozesuak batez beste ikasi duen ekintza kopurua agertzen da. Adibidez, pasta prestatzeko orduan, aditu batek hiru ekintza soilik identifikatu ditu derrigorrezko gisa. Modelatze-prozesuak 6.63 ekintza ikasi ditu batez beste. Horrek argi erakusten du hasierako ereduak ikasitako ereduetatik urrun daudela eta, beraz, ikasketaprozesuaren beharra dagoela eredu aberatsak eta zehatzak lortzeko.

3. taula. Batez beste ikasitako ekintzen kopurua, hasierako jarduera-ereduetan dagoen ekintza kopuruarekin aldaratuz. Emaitzak zortzi pertsonarentzako batezbesteko gisa agertzen dira.

\begin{tabular}{lcc}
\hline \multicolumn{1}{c}{ Jarduera } & $\begin{array}{c}\text { Ekintzak } \\
\text { hasieran }\end{array}$ & $\begin{array}{c}\text { Ikasitako ekintzak } \\
\text { batez beste }\end{array}$ \\
\hline Txokolatea prestatu & 2 & 5,6 \\
Telebista ikusi & 2 & 2,55 \\
Hortzak garbitu & 3 & 3,5 \\
Eskuak garbitu & 2 & 2,79 \\
Pasta prestatu & 3 & 6,63 \\
Liburua irakurri & 2 & 2,37 \\
Kafea prestatu & 2 & 6,36 \\
\hline
\end{tabular}

\section{ONDORIOAK}

Jarduera-eredu pertsonalizatu eta dinamikoak lortzeko ezinbestekoa da ekintza-sekuentzia ezberdinak ikastea pertsonako. Orain arte, arazo horri ez zaio heldu, baina lan honetan erakutsi da nola konpon daitekeen, ezagutzan 
eta datuetan oinarritutako modelatze-prozesuak konbinatuz. Hasteko, aditu batek ezagutzan oinarritutako jarduera-ereduak sortzen ditu, jarduera bakoitza exekutatzeko beharrezkoak diren ekintzak soilik identifikatuz. Ondoren, pertsona bakoitzak sortutako datuak erabiliz, ikasketa algoritmoak inplementatu dira, hasierako ereduak osatu eta espezializatzeko.

Diseinatu den modelatze-prozesua zortzi pertsonaren datuekin ebaluatu da. Emaitzek agerian utzi dute posible dela pertsona bakoitzarentzat eredu zehatzak ikastea, jarduera bakoitzaren aldaera ezberdinak behar bezala modelatuz. Sistemak, hala ere, eredu faltsu batzuk ere ikasten ditu, zenbaki absolutuetan gutxi badira ere. Eredu faltsu horiek sentsore-erroreen ondorio izan ohi dira. Oro har, eredua berriro ere aditu bati erakutsiz gero, erraza da faltsua dela identifikatzea. Baina modelatze-prozesuan bertan faltsua dela identifikatzeko, ezagutza gehiago eman behar zaio sistemari. Horrek hasierako ezagutza-mailaren arazoa dakar; hau da, zenbat ezagutza izan behar du hasieratik ikasketa-sistema batek? Galdera horrek ezin du erantzun bakarra izan. Domeinuaren arabera, ezagutza lortu eta modelatzea erraza bada, egokia litzateke sistemari ezagutza berori eskaintzea. Baina ezagutza hori lortzea nekeza bada, sistemak oinarrizko ezaguerarekin bakarrik egin beharko du lan, emaitzak aditu bati erakusteko azken pauso gisa. Lan honetan bigarren agertoki hori landu da.

\section{ESKER ONAK}

Lan hau Espainiako Gobernuaren diru laguntzei esker burutu ahal izan da, FRASEWARE proiektuan: TIN2013-47152-C3-3-R.

Bestalde, lan hau Gorka Azkune egilearen doktoretza tesian oinarritzen da.

\section{BIBLIOGRAFIA}

[1] M. PHILIPOSE eta K. FISHKIN. 2004. «Inferring activities from interactions with objects». Pervasive Comput., 3 (4), 50-57.

[2] T. FONG, I. NOURBAKHSH eta K. DAUTENHAHN. 2003. «A survey of socially interactive robots». Rob. Auton. Syst., 42, (3), 143-166.

[3] A. FERNÁNDEZ-CABALLERO. 2012. «Human activity monitoring by local and global finite state machines». Expert Syst. Appl., 39 (8), 6982-6993.

[4] L. CHEN, J. HOEY, C. NUGENT, D. COOK eta Z. YU. 2012. «Sensorbased activity recognition». IEEE Trans. Syst. Man, Cybern. C, 42 (6), 790 808.

[5] L. BAO eta S. INTILLE. 2004. «Activity recognition from user-annotated acceleration data». in Pervasive Computing, 1-17. 
[6] A. GALATA, N. JOHNSON eta D. HOGG. 1999. «Learning structured behaviour models using variable length Markov models». in IEEE International Workshop on Modelling People, 95-102.

[7] M. BRAND, N. OLIVER eta A. PENTLAND. 1997. "Coupled hidden Markov models for complex action recognition». in Proceedings of Computer Vision and Pattern Recognition, 994-999.

[8] P. RASHIDI eta D. COOK. 2013. «COM: A method for mining and monitoring human activity patterns in home-based health monitoring systems». ACM Trans. Intell. Syst. Technol., 4 (4), 64.

[9] B. BOUCHARD, S. GIROUX eta A. BOUZOUANE. 2006. «A Smart Home Agent for Plan Recognition of Cognitively-impaired Patients». J. Comput., 1 (5), 53-62.

[10] L. CHEN eta C. NUGENT. 2008. «A logical framework for behaviour reasoning and assistance in a smart home». Int. J. Assist. Robot. Mechatronics, 9 (4), 20-34.

[11] D. RIBONI eta C. BETTINI. 2011. «COSAR: hybrid reasoning for contextaware activity recognition». Pers. Ubiquitous Comput., 15 (3), 271-289.

[12] L. CHEN, C. NUGENT eta H. WANG. 2012. "A knowledge-driven approach to activity recognition in smart homes». Knowl. Data Eng. IEEE Trans., 24 (6) 961-974.

[13] L. CHEN, C. NUGENT eta G. OKEYO. 2014. «An Ontology-based Hybrid Approach to Activity Modeling for Smart Homes». IEEE Trans. HumanMachine Syst., 44 (1), 92-105. 